\title{
AFRICANIDADE E NEGRITUDE EM CONTEXTOS DIASPÓRICOS: UMA REFLEXÃO SOBRE A OBRA AMERICANAH, DE CHIMAMANDA NGOZIA DICHIE
}

\author{
NATACHA IRIA PEREIRA LOPES (UEPG) ${ }^{1}$ \\ MARLY CATARINA SOARES (UEPG) ${ }^{2}$
}

\begin{abstract}
RESUMO: O presente artigo tem o objetivo de refletir a respeito das diásporas modernas e das múltiplas identidades que advém destes movimentos migrantes, que caracterizam o contexto da globalização e da pós-modernidade. Objetiva-se também explanar algumas das consequências e dos impactos sociais causados pelo Imperialismo, que reverberam ainda na atualidade. Para isto, pretende-se analisar, sob o viés da multiculturalidade e dos distúrbios identitários causados pelos movimentos diaspóricos, a obra literária Americanah, escrita pela autora nigeriana Chimamanda Ngozi Adichie. Através da narrativa e da fundamentação teórica constituída por autores como Stuart Hall, Homi Bhabha, Kabengele Munanga, Kwame Anthony Appiah e Michel Agier, espera-se demonstrar a maneira como as migrações em massa resultam na formação de indivíduos culturalmente híbridos, o que os leva, por vezes, a experienciar sensações de não-pertencimento e conflitos internos acerca da própria identidade.
\end{abstract}

PALAVRAS-CHAVE: Diáspora. Identidade. Globalização. Cultura. Literatura.

ABSTRACT: This article aims to reflect about the modern diasporas and the multiple identities that come from these migratory movements, which characterize the context of globalization and postmodernity. Also, we intent to explain some of the consequences and social impacts caused by the Imperialism, that reverberate until the present. In order to do so, we will analyze, under the bias of multiculturalism and identity disorders caused by the diasporic movements, the novella Americanah, written by the Nigerian author Chimamanda Ngozi Adichie. Through the narrative and the theoretical foundation constituted by authors such as Stuart Hall, Homi Bhabha, Kabengele Munanga, Kwame Anthony Appiah and Michel Agier, we hope to demonstrate the way how massive migrations result on the constitution of culturally hybrid individuals, which leads them, sometimes, to experience sensations of non-belonging and internal conflicts regarding their own identity.

KEYWORDS: Diaspora. Identity. Globalization. Culture. Literature.

\section{INTRODUÇÃO}

O presente artigo tem o objetivo de explorar a temática das identidades em constante construção e movimento, a partir do viés das diásporas modernas e da globalização, trabalhadas por autores como Stuart Hall e Homi Bhabha. Para compreender o alcance deste contexto diaspórico a ser abordado, partiremos da afirmação de Hall (2003) de que os movimentos diaspóricos, livres ou forçados, só tem crescido desde o século XV, e constituem, hoje, mais a regra do que a exceção. Para o autor, este intenso fluxo de indivíduos marca a ruptura das sociedades culturalmente homogêneas e o fim do protagonismo do ocidente no contexto da globalização.

Isto ocorre devido ao fato de que estas minorias imigrantes, oriundas especialmente de países de terceiro mundo dos continentes Africano, Asiático e da América Latina, trazem consigo costumes e tradições originárias de seus locais de partida. Isto significa que, embora mantenham vínculos com suas culturas de origem, os indivíduos negociam com os costumes e

\footnotetext{
1 Mestranda em Estudos da Linguagem pela Universidade Estadual de Ponta Grossa (UEPG), e-mail: natacha.manson@gmail.com

2 Professora Doutora, Universidade Estadual de Ponta Grossa (UEPG), e-mail: marlycs@yahoo.com.br
} 


\section{$=$ TRAMA $=$}

tradições dos locais em que vivem, recebendo traços deste novo meio e imprimindo nele características de sua própria cultura. A este processo, Hall (2011) dá o nome de Tradução, ou seja, a capacidade dos indivíduos de exercerem trocas e negociações entre suas próprias tradições e as tradições do outro.

Com a intenção de ilustrar a maneira como esses processos de transformações e diálogos identitários ocorrem, tomaremos como base para este trabalho o romance Americanah, de autoria de Chimamanda Ngozi Adichie. Nesta obra, a autora procura demonstrar, através das situações vividas por sua personagem central, Ifemelu, imigrante nigeriana que parte em direção aos Estados Unidos, a maneira como estas trocas culturais

ocorrem. É importante frisar que, conforme demonstra Bhabha (2007), e como vemos na narrativa de Adichie (2014), essas trocas e negociações nem sempre são processos pacíficos: o contato entre as culturas é, muitas vezes, palco do encontro entre vozes dissidentes e de lutas de poder, dando origem a grupos oprimidos, como "mulheres, colonizados, grupos minoritários, os portadores de sexualidades policiadas." (BHABHA, 2007, p. 24)

Conforme veremos ao longo da obra da autora nigeriana, Ifemelu e tantos outros africanos que partem em direção ao Ocidente se encontram inscritos neste grupo que Hall chama de "diferente", "exterior" ou "abjeto" (2000, p. 110). Isto se deve ao fato de que, para o autor, a questão da identidade funciona também por meio da exclusão. No caso de Americanah, Ifemelu e os demais se descobrirão como indivíduos "à margem", por representarem o "outro": negros, imigrantes, com pouco domínio das condutas sociais exigidas pelo Ocidente.

Partindo dessas ideias, buscaremos explorar, ao longo do desenvolvimento deste artigo, temas centrais da obra de Adichie (2014), como a diáspora, o reconhecimento da identidade negra e do que é ser africano no ocidente, os choques e assimilações entre diferentes culturas e o desejo de retorno ao país de origem por parte daqueles indivíduos que fizeram parte dos processos diaspóricos.

Com o objetivo de alicerçar a análise que procederemos da obra em questão, nos serviremos das teorias pautadas por autores como Homi Bhabha, Stuart Hall, Kwame Anthony Appiah, Kabenguele Munanga e Michel Agier, que tratam a respeito de temas coerentes com o universo do romance, como o hibridismo, as identidades fluídas, os distúrbios identitários, a globalização e a diáspora.

\section{DOS MOVIMENTOS DIASPÓRICOS}

A narrativa retratada por Chimamanda Ngozi Adichie (2014) em Americanah tem início na década de 1990, na cidade de Lagos, na Nigéria. Nesta época, o país atravessava um período de regime militar, sob o governo dos generais Babangida, Abacha e Abubakar. Durante os anos em que estiveram no poder, conforme demonstra a narrativa de Adichie (2014), as forças militares permitiram o sucateamento das universidades nacionais, cujos professores estavam constantemente em greve por conta das condições subumanas nas quais se encontravam as universidades: não havia luz, água ou sequer giz nas salas de aula, e os salários dos professores e funcionários não eram pagos há meses.

As constantes paralisações levam um grande grupo de estudantes de toda a Nigéria, entre os quais está Ifemelu, protagonista do romance e estudante da Universidade de Nsukka, a fazerem exames admissionais para universidades americanas e inglesas, e solicitar seus vistos estrangeiros. Aqueles que são aceitos e recebem seus vistos de estudante são exaltados pela família, vizinhos e amigos, celebrados como aqueles que poderão experimentar o sonho de viver no exterior, em especial nos Estados Unidos, acalentado pelo consumo de programas de TV, produtos e alimentos que vendem o ideal americano. 


\title{
$=$ TRAMA $=$
}

Conforme uma grande massa de estudantes nigerianos começa a deixar o país em busca da conclusão de seus cursos superiores e da promessa de melhores condições de vida no exterior, tem início, no romance, o processo que Hall caracteriza como um "enorme movimento de pessoas das periferias para o centro, num dos períodos mais longos e sustentados de migração 'não planejada' da história recente." (2011, p. 81) De acordo com o autor, estas migrações, que podem se dar pelos mais diversos motivos (desde catástrofes naturais, pobreza ou guerras), são resultado de uma interdependência global. Neste contexto, as grandes potências econômicas, que acreditavam que poderiam sair ilesas das consequências causadas pelo imperialismo nas antigas colônias, descobrem que precisarão lidar com as migrações, para dentro de seu território, dos povos assolados pelos desdobramentos do colonialismo.

A respeito disso, escreve Adichie:

\begin{abstract}
A manchete era FALEM INGLÊS EM CASA, DIZ BLUNKETT A IMIGRANTES. Ele imaginou o artigo. Havia tantos assim nos jornais e apenas repetiam o que era dito no rádio e na televisão e até na conversa de alguns homens do depósito. O vento que soprava nas llhas Britânicas estava impregnado do cheiro do medo de quem pedia asilo, infectando a todos com o pânico de uma catástrofe iminente. Assim, esses artigos eram escritos e lidos, de forma simples e histérica, como se seus autores vivessem num mundo onde o presente não tinha ligação com o passado e nunca tivessem considerado que esse era o curso normal da história: a chegada em massa à Inglaterra de negros vindos de países criados pelo Reino Unido (ADICHIE, 2014, p. 281).
\end{abstract}

O trecho acima, retirado do romance Americanah, em que se pede que os imigrantes residentes na Inglaterra priorizem o uso da língua inglesa em detrimento de suas línguas de origem, demonstra o medo e o receio das antigas metrópoles de perder aquilo que Hall (2011) chama de "Identidades Nacionais" (p. 47), ou seja, um conjunto simbólico de ideias, características e tradições que habitam o imaginário popular e que traduziriam, aos olhos do mundo, o que significa pertencer a determinada nacionalidade. A linguagem é um desses traços marcantes para a constituição do ideal de nação, e o pedido para que os imigrantes priorizem a anglofonia em detrimento de seus idiomas de origem é um sintoma marcante da tentativa de manutenção dessas "comunidades imaginadas" (HALL, 2011, p. 51) e da xenofobia que reina, hoje em dia, sobre muitos países da Europa, com medo das consequências da imigração. Ainda de acordo com o autor, os ideais de grandeza e soberania que cercam essas comunidades imaginadas falham em mencionar que muito da riqueza de que esses países gozam foram conquistadas a partir de assimilações violentas de território, trazendo a extrema pobreza para outros continentes por eles explorados.

Além disso, a narrativa acerca das comunidades imaginadas não considera, de acordo com Hall (2011), as diferentes classes sociais e etnias que constituem uma nação, considerando que, com os processos migratórios, as populações europeias, por exemplo, já não são homogêneas, e sim formadas por diferentes povos, com traços culturais e linguísticos diversos. Em adição a isso, o autor menciona ainda o fato de que negros e imigrantes geralmente ocupam a escala mais baixa dessas sociedades estratificadas, como veremos a seguir em alguns recortes do romance. A partir disso, podemos argumentar que o pedido de que a língua inglesa seja falada pelos imigrantes, com a intenção de manter o que Hall chama de "englishness" (2011, p. 53), nada mais é do que uma tentativa débil de manter uma uniformidade cultural que já é, em si mesma, inexistente.

Para Hall (2003), o resultado dos movimentos diaspóricos e da expansão da globalização é a fundação de sociedades multiculturais, nas quais diferentes comunidades, com 


\section{$=$ TRAMA $=$}

tradições e características diversas, procuram construir uma existência em comum, ao mesmo tempo em que buscam preservar algo de sua identidade primordial. Logo, de acordo com o autor, este convívio e interação entre culturas representa a dissolução do ideal do estadonação, pautado na homogeneidade e em "valores universais, seculares e individualistas liberais". (HALL, 2003, p. 52)

Assim como a nova globalização privilegia, de acordo com Hall (2003), o global em detrimento do nacional, delimitando o enfraquecimento dos estados-nação, os movimentos de migração afetam diretamente os indivíduos que deles participam. Conforme pontua Agier (2001), o mundo pós-moderno é marcado por distúrbios identitários ligados a diversos aspectos da convivência social. Um deles, que nos interessa apontar neste artigo, advém da territorialidade, ou seja, do indivíduo que, em uma situação diaspórica, é movido de sua terra de origem e passa a não reconhecer a si próprio, precisando enfrentar um processo de reelaboração de sua identidade.

Para o autor, é relevante apontar que "o ponto de partida das buscas de identidade individuais ou coletivas é o fato de que somos sempre o outro de alguém, o outro de um outro (...) É necessário, então, pensar-se a si próprio a partir de um olhar externo, até mesmo de vários olhares cruzados" (AGIER, 2001, p. 9).

Percebe-se então que, de acordo com o teórico, a construção da identidade depende, em grande parte, de nossa relação com o outro, de olhares externos. Para Agier (2001), estes relacionamentos com o que é externo a nós nos permite reformular paradigmas que antes acreditávamos imutáveis, como os relacionados à raça e etnia, conforme analisaremos a seguir.

\section{IDENTIDADE, RAÇA E ETNIA: O QUE É SER NEGRO NA AMÉRICA?}

Para explorar o tema das identidades ligadas à raça e etnia no romance Americanah, partiremos da afirmação feita por Agier (2001) de que, no contato com o outro, reformulamos nosso conceito acerca de nós mesmos. Diante disso, é interessante ressaltar que, ao chegar aos Estados Unidos, a personagem Ifemelu, vinda da Nigéria, confronta-se pela primeira vez com a realidade das hierarquias raciais existentes na América, algo que não existia em seu país, onde existe uma maior homogeneidade étnica e racial. Além disso, diante deste paradigma, Ifemelu se dá conta, pela primeira vez, de que é negra. A respeito desta experiência, Ifemelu escreve em seu blog intitulado "Raceteenth ou Observações Diversas sobre Negros Americanos (Antigamente Conhecidos como Crioulos) Feitas por uma Negra Não Americana":

Querido Negro Não Americano, quando você escolhe vir para os Estados Unidos, vira negro. Pare de argumentar. Pare de dizer que é jamaicano ou ganense. A América não liga. E daí se você não era negro no seu país? Está nos Estados Unidos agora. Nós todos temos nosso momento de iniciação na Sociedade dos Ex-Crioulos. O meu foi numa aula da faculdade, quando me pediram para dar a visão negra de algo, só que eu não tinha ideia do que aquilo significava. Então, simplesmente inventei (ADICHIE, 2014, p. 239).

Ao afirmar para seus interlocutores africanos que "você não era negro no seu país", Ifemelu, evidentemente, não quer dizer que a cor da pele dos africanos alterava-se em seu local de origem, mas sim que, em um contexto onde a grande maioria das pessoas é negra, a cor da pele não é relevante. Isto vem corroborar a afirmação de que "é pela tomada de consciência das diferenças, e não pelas diferenças em si, que se constrói a identidade." (CUNHA, 1985, p. 206 apud MUNANGA, 2006, p. 20) É apenas em um contexto em que se depara com inúmeras cores de pele e características, ou seja, em que se confronta com o seu "outro", conforme Agier (2001), que a personagem passa a construir essa nova posição-de-sujeito (Hall, 2000, p.112). 


\section{$=$ TRAMA $=$}

Logo que chega aos Estados Unidos e passa a morar com sua tia, Uju, Ifemelu descobre que, nos Estados Unidos, existe uma categoria racial denominada de hispânicos, como a babá Alma: "Se Ifemelu tivesse conhecido Alma em Lagos, a teria considerado branca, mas ali aprenderia que Alma era hispânica, uma categoria americana que, para confundir, era tanto etnia quanto raça..." (ADICHIE, 2014, p. 116)

Diante dessas novas descobertas, e abordando a questão das hierarquias raciais nos Estados Unidos, Ifemelu relata em seu blog:

Hispânicos são frequentes companheiros dos negros americanos nos índices de pobreza, um pequeno passo acima deles na hierarquia racial do país. A raça inclui a mulher de pele chocolate do Peru; os povos indígenas do México; pessoas com cara de mestiças da República Dominicana; pessoas mais branquinhas de Porto Rico; e o cara louro de olhos azuis da Argentina. Você só precisa falar espanhol e não ser da Espanha e, voilà, pertence a uma raça chamada hispânico (ADICHIE, 2014, p. 116).

A respeito do fato de que formam-se, nos Estados Unidos, categorias sociais baseadas em fatores como a cor da pele, a linguagem e a origem de determinados grupos, podemos afirmar que constrói-se, neste contexto, o que Munanga (2006, p. 20) chama de "identidade legitimadora". O autor define esta construção social, construída a partir das relações de poder, como uma forma de identidade elaborada pelas categorias sociais dominantes, com a intenção de justificar e racionalizar seu domínio sobre os demais.

Neste sentido, podemos afirmar que há de fato a constituição de uma identidade legitimadora (Munanga, 2006, p. 20), uma vez que os negros, nos Estados Unidos, não veem a si mesmos ao buscar por imagens de poder, exercidas quase que completamente por pessoas brancas. Desta forma,

uma pessoa ou grupo de pessoas pode sofrer um prejuízo ou uma deformação real se as pessoas ou as sociedades que os rodeam thes devolvem uma imagem limitada, depreciativa ou desprezível delas mesmas. O não reconhecimento ou reconhecimento inadequado pode causar prejuízo ou uma deformação de opressão, ao aprisionar alguns num modo de ser falso, deformado e reduzido (TAYLOR, 1994, p. 41 apud MUNANGA, 2006, p. 28).

Levando em conta a intensa falta de representatividade da comunidade negra dentro das esferas de poder social e político nos Estados Unidos, é compreensível que Ifemelu, já residindo no país há mais de uma década neste ponto da narrativa, assista com grande emoção e entusiasmo à vitória, no ano de 2008 , do presidente Barack Obama, primeiro político negro a ser eleito para o cargo na América do Norte. A personagem descreve a vitória de Obama como um momento de intenso sentimento de comunidade, partilhado não apenas com seus amigos e familiares, mas com o que pareceu a ela toda uma nação:

Barack Obama às vezes falava mais alto e às vezes mais baixo, com uma expressão solene no rosto e, em torno dele, havia uma imensa e resplandecente multidão de esperançosos. Ifemelu assistiu àquilo hipnotizada. $E$, naquele momento, não havia nada mais belo para ela do que a América (ADICHIE, 2014, p. 390).

Para Munanga (2006), a história dos negros nos Estados Unidos precisou definir-se desde o início por um sentimento de coletividade. De acordo com o autor, o próprio fato de serem mantidos como escravos, até o ano de 1868, em um país construído sobre os princípios de igualdade e liberdade, gera na sociedade negra um senso de cooperação frente à necessidade de manter sua existência e proteger-se. 


\title{
$=$ TRAMA $=$
}

Ainda a respeito da eleição de Obama, Ifemelu escreve em seu blog um texto intitulado "Obama é alguma coisa além de negro?"

\begin{abstract}
Muita gente — principalmente quem não é negro — diz que Obama não é negro, é birracial, multirracial, mestiço, qualquer coisa menos simplesmente negro. Porque a mãe dele era branca. Mas raça não é biologia; raça é sociologia. Raça não é genótipo; é fenótipo. A raça importa por causa do racismo. E o racismo é absurdo porque gira em torno da aparência. Não do sangue que corre nas suas veias. Gira em torno do tom da sua pele, do formato do seu nariz, dos cachos do seu cabelo (ADICHIE, 2014, p. 366).
\end{abstract}

Hall (2003, p. 69) corrobora a afirmação feita por Adichie (2014) de que a categoria "raça" não é fundamentada em conceitos biológicos, e sim sociais. O autor afirma que a cor da pele não é suficiente para delimitar recortes raciais, uma vez que "o espectro de cor entre os afro-caribenhos é extremamente amplo" (e também o é entre nigerianos, afro-americanos, hispânicos, etc.). Desta forma, de acordo com o teórico, o conceito de raça não é científico, e sim um construto político e social no qual se fundamenta o racismo - ou seja, um sistema de exclusão e exploração política, econômica e social.

Appiah (2007) vem reforçar as asserções de Hall (2003) e Adichie (2014), pontuando:

Qualquer biólogo bem conceituado há de concordar em que a variabilidade genética humana que diferencia as populações da África, da Europa ou da Ásia não é muito maior que a existente dentro dessas mesmas populações, ainda que o "muito maior" dependa, em parte, da medida de variabilidade genética que o biólogo escolher. (..) À parte das características morfológicas visíveis da pele, cabelos e ossos, pelas quais nos inclinamos a incluir as pessoas nas mais amplas categorias raciais - brancos, negros, amarelos - poucas são as características genéticas encontráveis na população da Inglaterra que não se encontrem, em proporções similares, no Zaire ou na China (APPIAH, 2007, p. 62).

O autor afirma também que a classificação dos indivíduos em raças só poderia ser relevante, do ponto de vista biológico, se os traços genéticos das populações mundiais não houvessem se fundido grandemente devido aos movimentos migratórios. Esta fusão, segundo Appiah (2007), faz com que existam milhões de seres humanos que não podem ser encaixados em nenhuma categoria de raça específica.

Em adição a todos esses fatores envolvendo a raça, a personagem Ifemelu precisa ainda confrontar-se, nos Estados Unidos, com o que é ser, além de negra, uma mulher africana. Analisaremos, a seguir, como a questão da africanidade é retratada no romance Americanah.

\section{O QUE É A ÁFRICA NA VISÃO NORTE-AMERICANA?}

Para compreender o que significa o termo "África" na visão estadunidense, devemos partir da afirmação de Hall de que "o termo 'África' é, em todo caso, uma construção moderna, que se refere a uma variedade de povos, tribos, culturas e línguas cujo principal ponto de origem comum situava-se no tráfico de escravos." (2003, p. 31) Isto demonstra, conforme argumentaremos através de trechos do romance Americanah, que o conceito acerca do que seria a África é uma criação ocidental, que considera o continente como um grande bloco homogêneo, ignorando a ampla diversidade cultural existente naquele território.

Além disso, de acordo com Bhabha (2007) a imagem que habita o imaginário popular ocidental do que seria a África é ainda marcada por "estereótipos de primitivismo e degeneração." (p. 73) Para Hall (2003), esta perspectiva, permeada por ideias de pobreza extrema e subdesenvolvimento, é o legado do Imperialismo, que assolou comunidades inteiras e espalhou a miséria pelo mundo. No caso específico do continente em questão, a partilha da 


\section{$=$ TRAMA $=$}

África pelas potências europeias no Congresso de Berlim marca a expropriação da terra e a destruição dos recursos de subsistência dos quais os povos africanos retiravam seu sustento, conforme demonstra Munanga (2007).

No entanto, segundo Hall (2002) e de acordo com o romance de Adichie (2014), esta imagem nem sempre reflete a realidade do continente africano como um todo. Para o autor, embora o alcance da globalização seja menor na periferia em relação ao centro, mesmo aqueles indivíduos residentes em áreas remotas, de países pobres e subdesenvolvidos, podem receber influência da cultura ocidental consumista, através de aparelhos de TV, rádio e computadores conectados à Internet. Adichie (2014) escreve a respeito da casa do personagem Obinze, na Nigéria: "Os cômodos estariam todos frescos, com as palhetas de ventilação do arcondicionado movendo-se em silêncio, a cozinha cheiraria a curry e tomilho, a CNN estaria ligada no andar de baixo, enquanto a televisão do andar de cima mostraria a Cartoon Network, e saturando tudo haveria o ar imperturbado do bem-estar" (ADICHIE, 2014, p. 29).

Esta passagem, embora retrate a realidade de um personagem economicamente privilegiado, contraria a imagem tribal, selvagem e naturalista do africano acalentada pelo Ocidente. Percebemos, através do trecho, que é possível, pelo menos para uma parcela dos nigerianos, ter acesso à tecnologia e às notícias veiculadas naquilo que Hall (2002) chama de "aldeia global", ou seja, uma grande rede de informações em constante movimento que viajam ao redor do globo, formando uma teia que conecta todos aqueles que tem acesso a ela.

No romance, Ifemelu consegue seu primeiro emprego nos Estados Unidos trabalhando como a babá dos filhos de uma família branca e abastada, residente nos subúrbios da Filadélfia. Em uma festa da qual participa acompanhando a patroa, Ifemelu depara-se com o estereótipo do continente africano pobre, unificado e assolado pela fome e pelas doenças.

Ao descobrirem que Ifemelu é nigeriana, os convidados da festa, membros da elite branca americana, passam a relatar histórias, geralmente ligadas a atos de caridade, a respeito dos mais diversos países africanos que ajudam ou que já visitaram:

Um casal falou de seu safári na Tanzânia. "Nosso guia era maravilhoso e agora estamos pagando os estudos da filha mais velha dele." Duas mulheres falaram de suas doações a uma instituição de caridade maravilhosa do Malaui que furava poços, a um orfanato maravilhoso em Botsuana, a uma cooperativa de microfinanciamento no Quênia. (...) Uma mulher franzina de paletó cor-de-rosa de corte severo disse: "Sou presidente do conselho de instituição de caridade que atua em Gana. Trabalhamos com mulheres do campo. Estamos sempre interessados em contratar funcionários africanos, não queremos ser aquela ONG que não usa a mão de obra local" (ADICHIE, 2014, p.185).

Estas declarações, feitas por inúmeras pessoas, é um reflexo da imagem que os ocidentais nutrem de uma África que se traduz apenas como um reduto de miséria e desolação, em constante busca por ações sociais e atos de caridade que as elites mundiais sentem a necessidade de declarar. Esta visão ignora o fato de que a África não é um local homogêneo, e sim berço de diversas manifestações culturais que seguem obscurecidas pela imagem de aridez, privação e fome. Além disso, o fato de que, mesmo sabendo que Ifemelu é especificamente nigeriana, ninguém tenha citado o país em suas falas, é sintomática do fato de que, para eles, a África é apenas um grande bloco indiferenciado.

Ainda em outra ocasião, ao procurar um salão especializado em tranças, dirigido por três mulheres africanas, Ifemelu envolve-se no seguinte diálogo com a cabeleireira Aisha, senegalesa que corrobora mais uma vez a compreensão que os ocidentais tem da África como homogênea. Ao perguntar onde mora a irmã de Aisha, Ifemelu recebe a resposta de que é "na África" (ADICHIE, 2014, p. 22): 


\section{$=$ TRAMA $=$}

"Por que você diz que ela mora na África em vez de dizer o país?", perguntou Ifemelu. Aisha deu uma risadinha. "Você não conhece os Estados Unidos. Você fala em Senegal para os americanos e eles dizem 'Onde fica isso?'. Minha amiga de Burkina Fasso, eles perguntam pra ela 'Seu país é na América Latina?' (ADICHIE, 2014, p. 22-23).

Após alguns meses vivendo nos Estados Unidos e já frequentando a universidade, Ifemelu conhece, através de uma colega de classe vinda do Quênia, uma instituição denominada "Associação de Estudantes Africanos". Neste grupo, reuniam-se diversos estudantes, vindos de diferentes países da África, com a intenção de formar uma rede de apoio de incentivo mútuo, conversando, trocando histórias e procurando, através do contato com seus semelhantes (todos negros, africanos e imigrantes) abrandar a saudade que sentiam de seus locais de origem. Os membros do grupo estendem uns aos outros sua cooperação em amizade, além de compreenderem as experiências vividas uns pelos outros em solo americano com relação a questões como o preconceito e o racismo. "Eles contavam, brincando, o que os americanos Ihes falavam: Você fala inglês tão bem. Tem muita aids no seu país? É tão triste que as pessoas vivam com menos de um dólar por dia na África." (ADICHIE, 2014, p. 152)

Ao explanar o tema da diáspora, Hall (2003) afirma que, em contextos de migração, há a tendência à formação de "comunidades diaspóricas" (p. 66), ou seja, indivíduos que unem-se em torno de um senso de identidade grupal, devido a origens ou características em comum. $\mathrm{O}$ autor afirma que "As chamadas 'minorias étnicas' de fato têm formado comunidades culturais fortemente marcadas e mantêm costumes e práticas sociais distintas na vida cotidiana, sobretudo nos contextos familiar e doméstico." (HALL, 2003, p. 65)

No entanto, o autor julga importante salientar que, ainda que possuam traços em comum, essas comunidades étnicas possuem diferenças dentro de si mesmas. Para exemplificar esta afirmação, o autor cita o caso dos asiáticos que, embora tenham traços culturais e físicos semelhantes, possuem traços religiosos, gastronômicos, linguísticos e étnicos diferenciados.

Podemos afirmar que na "Associação de Estudantes Africanos" frequentada por Ifemelu, temos um exemplo de formação de uma comunidade diaspórica. São indivíduos que unem-se por conta de características e vivências em comum, procurando manter traços de suas culturas de origem, como a culinária, as histórias e tradições orais de seus países, seu sotaque, entre outros aspectos. Porém, assim como salientado por Hall (2003), à maneira dos asiáticos, os africanos também possuem diferenças culturais entre si.

Podemos afirmar então que, no caso de Ifemelu e dos demais estudantes provenientes do continente africano, as diferenças podem ser relegadas a segundo plano diante da necessidade de agrupar-se em torno de identidades conhecidas, familiares e compartilhadas por todos aqueles indivíduos.

É interessante ressaltar, no entanto, que em outro contexto (o de estar na África, por exemplo) essas diferenças que são ignoradas nos Estados Unidos poderiam ser relevantes. Uma forma de argumentar contra a ideia de que o continente africano é composto por uma cultura única é analisar os preconceitos e diferenças manifestados por etnias diversas dentro da própria Nigéria.

Um exemplo disso é o fato de que Ifemelu, integrante da etnia igbo, quando retorna para a Nigéria vê-se na necessidade de alugar um apartamento. Ao procurar, encontra a recusa de um homem de etnia diferente que afirma que "Eu não alugo para os igbos. (...) Essa é a minha regra desde que um homem igbo destruiu minha casa em Yaba." (ADICHIE, 2014, p. 424) Para a surpresa de Ifemelu, ela consegue alugar a casa após contar ao homem que 


\section{$=$ TRAMA $=$}

acabara de retornar dos Estados Unidos, o que pode sugerir que a experiência no exterior, em alguns casos, pode sobrepor-se à sua etnia, ou sua identidade de origem.

\section{O RETORNO À ÁFRICA: AMERICANAH}

De acordo com Hall (2003), existe uma crença popularmente difundida de que nossa identidade cultural é firmada no nascimento, sendo parte de nossa natureza e constitutiva de um "eu" essencial. Logo, conforme coloca o autor, esperamos que esta identidade não seja permeada por "algo tão 'mundano', secular e superficial quanto uma mudança temporária de nosso local de residência." (HALL, 2003, p. 28) Em outras palavras, os seres humanos carregam a ilusão de seguirem sendo os mesmos em seus costumes e identidades após a experiência da diáspora.

Esta suposta imutabilidade faz com que esses imigrantes sigam carregando consigo um senso de grande identificação e pertencimento à pátria de origem, o que faz com que muitos deles acreditem naquilo que Hall (2003, p. 28) chama de "retorno redentor". O desejo de retornar ao seio familiar, a um local de costumes e pessoas conhecidos, acomete também a personagem Ifemelu. Mesmo após quase quinze anos vivendo nos Estados Unidos, e tendo se tornado uma cidadã americana, Ifemelu anseia pela volta à Nigéria, pela retomada das velhas amizades e das velhas tradições, das quais sente falta. Sendo assim, a personagem decide voltar ao seu país de origem e reconstruir sua vida lá.

Para sua surpresa, logo que chega à cidade de Lagos, Ifemelu experimenta um intenso choque cultural: após todos os anos passados na América, a personagem sente-se agredida pelo clima da Nigéria, pelo trânsito caótico, pelas pilhas de lixo que se acumulavam nas ruas, pelos prédios decrépitos com a pintura descascando e pela paisagem em geral à sua volta. $O$ narrador descreve que, neste momento de conflito e desentendimento "Ifemelu teve a sensação estonteante de que caía, caía dentro dessa nova pessoa que se tornara, caía no estranho familiar. Será que sempre tinha sido daquele jeito ou tinha mudado tanto em sua ausência?" (ADICHIE, 2014, p. 415)

Este estranhamento, conforme podemos ver em Hall (2000) pode dar-se por dois motivos. O primeiro deles é que, em um desejo de manter memórias afetivas de suas comunidades de origem, pessoas como Ifemelu alimentam a lembrança de tradições, paisagens e características imaginadas ou idealizadas. Além disso, esquece-se, segundo o autor, que estes locais estão também sujeitos à influência da globalização e, assim como as identidades, estão envolvidos em constante processo de modificação e reinvenção. Ao estar distante deste espaço por mais de uma década, Ifemelu não acompanhou as mudanças sofridas por seu país, e chocou-se ao se deparar com uma imagem nova de seu local de origem:

Quando Ifemelu fora embora, só os ricos tinham celulares, todos o números começavam com 090 e as meninas queriam namorar os homens do 090. Agora, a moça que trançava seu cabelo tinha um celular, o vendedor de banana-da-terra que cuidava de uma grelha empretecida tinha celular. Ela crescera conhecendo todos os pontos de ônibus e ruas laterais, compreendendo o código secreto dos motoristas e a linguagem corporal dos ambulantes de rua. Agora, lutava para entender o que não era dito (ADICHIE, 2014, p. 416).

Sua nova maneira de encarar a realidade da Nigéria rende a Ifemelu o apelido de "americanah". Este termo já era um velho conhecido da personagem, uma vez que era a maneira como ela e seus amigos costumavam chamar aqueles que, em sua infância e adolescência, passavam períodos nos Estados Unidos e retornavam afetando trejeitos 


\title{
$=$ TRAMA $=$
}

adquiridos no exterior. Por exemplo, quando sua amiga Ginika mudou-se para a América, Ifemelu brincou com as demais colegas:

\begin{abstract}
"Ela vai voltar uma tremenda de uma americanah, que nem a Bisi", disse Ranyinudo. Todas urraram de rir com a palavra americanah, enfestoada de alegria com sua quinta sílaba estendida, e ao pensar em Bisi, uma menina um ano abaixo delas que voltara de uma breve viagem aos Estados Unidos com estranhas afetações, fingindo que não entendia mais ioruba e acrescentando um erre arrastado a todas as palavras em inglês que falava (ADICHIE, 2014, p. 74).
\end{abstract}

Ao ouvir esta palavra tão conhecida utilizada para definir a si mesma, Ifemelu compreende-se como estando naquilo que Bhabha (2007, p. 20) chama de "entre-lugares", ou seja, como fazendo parte de um local intersticial, além de suas identidades originárias. Desta forma, Ifemelu percebe que é agora reconhecida como uma "americanah" por seus colegas nigerianos, enquanto que, nos Estados Unidos, é reconhecida como uma africana.

Para Bhabha (2007), "esses entre-lugares fornecem o terreno para a elaboração de estratégias de subjetivação - singular ou coletiva - que dão início a novos signos de identidade e postos inovadores de colaboração e contestação, no ato de definir a própria ideia de sociedade" (p.20).

Em suma, isto significa dizer que o romance Americanah, que reflete a realidade não só da personagem Ifemelu, mas de milhões de imigrantes das mais diversas áreas do globo, é uma narrativa que ilustra a ressignificação e a tomada de consciência de si próprio e de sua identidade através do contato com o outro. Considerando a afirmação de Hall (2003) de que os movimentos migratórios constituem, hoje, a regra e não a exceção, podemos afirmar que a obra de Adichie é uma alegoria do mundo pós-moderno, em que as fronteiras se confundem, construindo identidades culturais, nacionais e subjetivas múltiplas, híbridas e fluídas.

\section{CONSIDERAÇÕES FINAIS}

Através do desenvolvimento deste artigo, pudemos refletir a respeito da condição subalterna do imigrante no mundo globalizado. Percebemos a narrativa de Adichie (2014) como uma obra literária de grande relevância na contemporaneidade, por ser uma representação da realidade de milhares de pessoas que deixam sua terra todos os anos, em busca de melhores condições de vida em países ocidentais de primeiro mundo, em especial os Estados Unidos.

Através do embasamento teórico elencado ao longo do artigo, foi possível pensar a respeito do impacto social e histórico causado pelo imperialismo, cujas consequência reverberam até os dias de hoje, assolando diversas comunidades e suscitando movimentos migratórios que moldam as sociedades atuais. O romance de Adichie (2014) ilustra com bastante clareza a maneira como estas relações sociais são construídas e os impactos que delas resultam.

Além disso, a realização desta pesquisa nos permitiu perceber a maneira como as sociedades ocidentais são estratificadas e tem suas hierarquias definidas, em grande parte, através do conceito de raça. Conceito este que, conforme vemos em Hall (2003) e Appiah (2007), não passa de uma divisão social imaginária, criada com o objetivo de reiterar a dominação das elites (majoritariamente brancas) sobre os grupos de negros e imigrantes. Esta questão aponta mais uma vez a obra Americanah como sendo deveras significativa, uma vez que lança mão de estratégias narrativas para oferecer ao leitor a visão de indivíduos oprimidos sobre temas como o racismo e a xenofobia.

É válido também ressaltar a obra de Adichie (2014) como algo capaz de abrir os olhos dos leitores não-africanos a respeito da diversidade cultural do continente africano. Isto ocorre 
uma vez que a autora ressalta, repetidamente, que o conceito de "África" como bloco homogêneo, marcado pela fome, doença e miséria, é algo irreal. A obra demonstra que o continente é berço de múltiplas culturas, além de ser também alvo da globalização e da disseminação de valores ocidentais, desconstruindo a imagem do "africano selvagem" tão difundida na sociedade ocidental.

Por fim, a obra é capaz de demonstrar, através da trajetória e da constante transformação da personagem Ifemelu, que as identidades do homem são fluídas e mutáveis, estando em constante movimento e alteração. Americanah é um perfeito exemplo de que, conforme coloca Agier (2001), as identidades são construídas através do contato com o outro, a partir do diálogo entre o diferente e o familiar.

É relevante ressaltar também que, por tratar-se de uma obra literária contemporânea, de uma escritora negra, jovem, africana e também imigrante, o romance Americanah é um meio de dar voz a grupos sociais oprimidos. A obra revela, através do ponto de vista de alguém que já atravessou as mesmas questões retratadas no livro, as agruras que as populações menos favorecidas são obrigadas a atravessar no mundo capitalista ocidental, e clama pelo desenvolvimento de uma consciência social e da empatia em relação a esses grupos.

Com base na bibliografia consultada e no romance de Adichie (2014), podemos afirmar que a realidade do mundo pós-moderno é a do hibridismo, da migração e do diálogo entre diversas culturas. Isto significa dizer que não vivemos mais em uma era de culturas unificadas, mas sim em um contexto multicultural, marcado pela pluralidade e pela globalização, mas também pelas desigualdades e injustiças sociais que a obra busca denunciar.

\section{REFERENCIAL BIBLIOGRÁFICO}

ADICHIE, C. N. Americanah. São Paulo: Companhia das Letras, 1a ed., 2014.

AGIER, M. Distúrbios identitários em tempos de globalização. Mana, Oct. 2001, vol.7, no.2, p.7-33. APPIAH, K. A. Na casa do meu pai: A África na filosofia da cultura. Rio de Janeiro: Contraponto Editora, 2a ed., 2007. BHABHA, H. O local da cultura. Belo Horizonte: EDUFMG, 2007.

CUNHA, M. C. Negros estrangeiros: Os escravos libertos e sua volta à África. São Paulo: Brasiliense, 1985

HALL, S. A Identidade Cultural na Pós-Modernidade. Rio de Janeiro: DP\& A, 2002

Da Diáspora: identidades e mediações culturais. Org. Liv Sovik. Belo Horizonte: Editora UFMG,

Brasília: Representação da UNESCO no Brasil, 2003.

Quem precisa de identidade? In: Silva, Tomaz Tadeu da (org.). Identidade e diferença: A perspectiva dos Estudos Culturais. Petrópolis: Editora Vozes, 2000. p. 103-133.

MUNANGA, K. Construção da identidade negra no contexto da globalização. In: DELGADO, Ignacio G. (org). Vozes da África: tópicos sobre identidade negra, literatura e história africanas. Juiz de Fora: Ed UFJF, 2006. TAYLOR, C. Multiculturalismo. Difference et démocratie. Paris: Aubier, 1994. 